\title{
Erratum to: Having a Say: Agency and End-of-Life Decision-making in The Chaneysville Incident
}

LaVera Crawley, MD, MPH

Stanford University Center for Biomedical Ethics, Stanford, CA, USA.

$\mathrm{J}$ Gen Intern Med 25(12):1384

DOI: $10.1007 / \mathrm{s} 11606-010-1499-2$

(c) Society of General Internal Medicine 2010

Erratum to: J Gen Intern Med

DOI 10.1007/s11606-010-1384-z

7 he opening page of the original publication should have 1 contained the following copyright credit notice: "Excerpts (sixty-two lines) from pp. 38, 39, 40, 50, 62, 63, 430 from THE CHANEYSVILLE INCIDENT by DAVID BRADLEY, Copyright () 1981 by David H. Bradley, Jr. Reprinted by permission of HarperCollins Publishers."

The online version of the original article can be found at http://dx.doi. org/10.1007/s11606-010-1384-z.

Published online August 31, 2010 